\title{
Subset Optimization of Adaptive Coding and Modulation Modes According to DVB-S2X
}

\author{
Chuang Wang ${ }^{1}$, Dongming Bian ${ }^{1}$ a, ${ }^{*}$, Feilong $\mathrm{Li}^{2}$, Yongqiang $\mathrm{Li}^{1}$ and $\mathrm{Jing}_{\mathrm{Hu}}{ }^{1}$ \\ ${ }^{1}$ Army Engineering University of PLA, Nanjing 210007, China; \\ 2People's Liberation Army troop's 31006, China. \\ *, a biandm_satlab@163.com
}

Keywords: Adaptive, Modulation, Subset Optimization.

\begin{abstract}
With the increasing requirement in satellite communication, Digital Video Broadcasting-Satellite extension (DVB-S2X) standard is proposed to reach higher efficiency. DVB-S2X provides 112 adaptive coding and modulation modes to get high efficiency which approaches the Shannon limit. However, with the entire modes adopted in a system, the complexity will rapidly increase. To balance the efficiency and complexity, this paper puts forward an algorithm based on rainfall probability to optimize the mode subset. The simulation shows that with fewer modes optimized by the proposed algorithm, the spectral efficiency almost reaches that of the entire modes.
\end{abstract}

\section{Introduction}

The second generation Digital Video Broadcasting-Satellite (DVB-S2) standard was firstly put forward in 2003, which has played a significant role in broadband satellite [1]. However, with the increasing growth of broadcasting, multimedia communication and interactive services, higher efficiency in spectrum is urgently required. In 2014 European Telecommunication Standards Institute (ETSI) approved the optional extensions of the S2 system identified by the denomination of DVB-S2 extension (DVB-S2X), which maintains the main structure of DVB-S2. The DVB-S2X standard provides a significant increase in the range and scope of the DVB-S2 specification that will improve operating performance in the core markets as well as increase operating range to cover emerging markets such as mobile and professional applications [2].

The most striking feature involved in DVB-S2 lies in Adaptive Coding and Modulation (ACM), with which the radio resources in different challenging environment can be used to the utmost [3]. DVB-S2 presents four modulation schemes, i.e., QPSK, 8PSK, 16APSK and 32APSK and eleven channel coding rates based on concatenated LDPC and BCH coding, which spread from 1/4 to 9/10. The combination scheme consists of 28 different Modulation and Coding (MODCOD) transmission modes. DVB-S2X provides different MODCOD modes as well. Besides, more efficient and more robust MODCOD modes are offered, and the granularity in MODCOD modes is increased. The quantity of MODCOD modes has grown from 28 of DVB-S2 to 112 of DVB-S2X, which make the efficiency approach the theoretical Shannon limit as close as possible [4].

However, it is not sensible to adopt all the MODCOD modes in ACM technique [5, 6]. Because with the number of adopted MODCODs increasing, the improvement of average spectral efficiency soon becomes saturation, and at the same time the switching rate among different MODCODs increases rapidly, which will lead to more complexity for system. Therefore, it is imperative to optimize the MODCOD subset. Reference [5-7] have proposed some procedures based on DVB-S2 to decrease the number of MODCODs and these results show that with fewer MODCODs, it can reach almost the same performance compared with the entire MODCODs. However, the procedures mentioned above are put forward based on MODCODs of DVB-S2, and more importantly the method they proposed is according to a specific rainfall environment. As we all know, in most parts of the world the total time of rain is much less than that without rain, thus these methods are somewhat of 
occasionally, limitation and non-universality. In this paper we propose an algorithm based on rainfall probability to optimize the MODCOD subset according to the DVB-S2X standard.

The rest of the paper is organized as followed. Besides briefly introduction of the innovation and advantage of DVB-S2X standard, the emphasis in Section II is given to the MODCODs analysis in DVB-S2X. Next, section III describes the optimization algorithm for the subset selecting. Section IV presents the assumptions and the simulations of different environment are analyzed in terms of the higher spectral efficiency. Finally, Section V concludes the paper.

\section{Description of Modoc Schemes in Dvb-S2x}

ETSI proposed the DVB-S2X standard in 2014 to support the traffic of increasing volumes in data, video and voice over satellite. The DVB-S2X standard is an extension of the DVB-S2. Accordingly the technique of ACM is not only remained, but also enhanced. The main principle of ACM is that when a user is under a heavy rain, the channel environment is abominable, and the robust MODCOD mode with lower order modulation and smaller coding rate is used to insure the basic communication, and when the sky is clear, the channel environment is reliable, then the efficient MODCOD mode with higher order modulation and larger coding rate is used to acquire more efficiency. Therefore, with the technique of ACM the communication channel is flexible and adaptable.

Compared with DVB-S2, DVB-S2X has made a series of improvements which enhance overall performance over satellite links through many innovative technologies. The innovative technologies are listed below: smaller roll-off factor, advanced filter technology, additional scrambling sequences, higher modulation modes, very low SNR MODCODs and increased granularity in MODCOD [4]. Among them ACM is the key. However, DVB-S2X standard supplies so many MODCODs. If all MODCODs are applied in a system, it may not meet expectations in spectrum efficiency. On the contrary, the whole system may be complicated and inefficient.

The modulation modes provided by DVB-S2X standard consist of BPSK, QPSK, 8PSK, 8APSK, 16APSK, 32APSK, 64APSK, 128APSK and 256APSK. And also coding rates vary greatly from $1 / 5$ to 9/10. There are 112 MODCODs in DVB-S2X including the legacy of DVB-S2. When we decide to optimize the subset, it is necessary to grasp the performance of each one at first. However, the standard just tells us part of the error performance. Besides, the precondition in which error performance obtained between DVB-S2 and DVB-S2X is discordance, so it is not sensible to just mix with them.

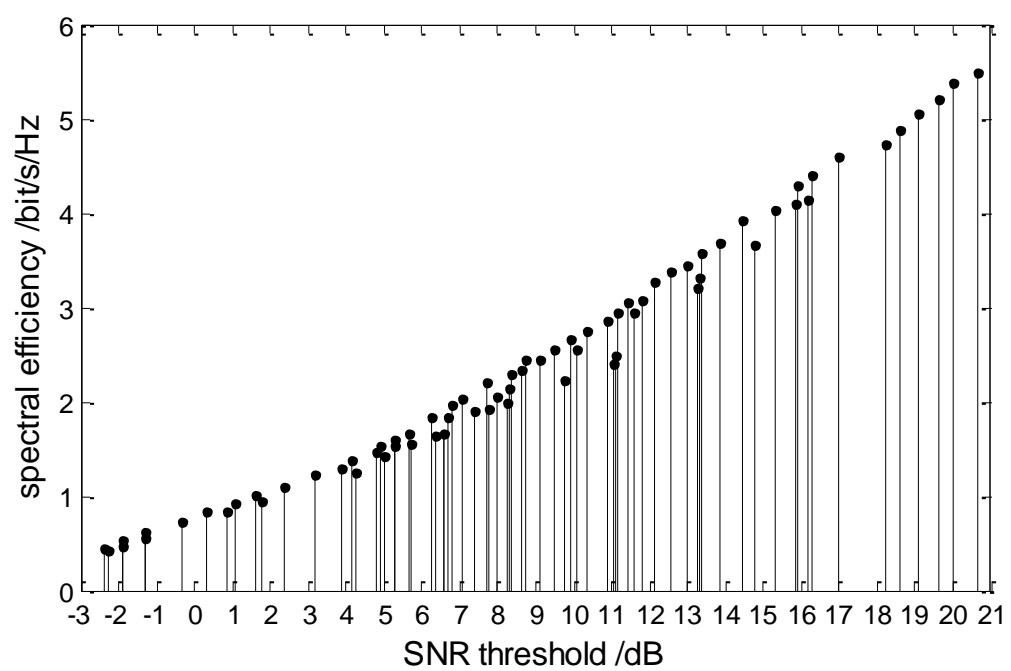

Figure 1. Performance of each MODCOD

Reference [8] provides most of the error performance except for the very low SNR MODCODs. Then we decide to do the research based on it. The performance of each MODCOD is depicted in Fig. 1. It should be noted that the SNR threshold and the corresponding spectral efficiency is obtained under the condition of $1 \times 10-7$ bit error rate with inserted pilots, $5 \%$ roll-off factor, and $36 \mathrm{MHz}$ transponder bandwidth of multicarrier transponder. Figure 1 shows that the maximum spectrum 
efficiency is $5.50 \mathrm{bit} / \mathrm{s} / \mathrm{Hz}$, where the corresponding SNR threshold is $20.63 \mathrm{~dB}$ and the minimum spectrum efficiency is $0.46 \mathrm{bit} / \mathrm{s} / \mathrm{Hz}$, where the corresponding SNR threshold is $-2.40 \mathrm{~dB}$. Also we can find that with the increase of SNR threshold, not all MODCODs' efficiency grow in the meanwhile. In addition, some remains, and the worst case is that some pulls down. Accordingly, the preliminary step is to prune away those achieve lower spectral efficiency at higher SNR threshold and pick out the best among those with nearby SNR threshold. After preliminary filter, the remaining 43 MODCODs are listed in Table 1. It should be noted that the MODCODs with a suffix of $-\mathrm{L}$ means that the constellation ring ratios have been optimized for quasi-linear channel whereas the non-suffix is optimized for the AWGN channel [2].

Table 1. Performance of Remaining MODCODs

\begin{tabular}{|c|c|c|c|c|c|c|c|c|c|c|c|}
\hline NO. & MODCOD & $\begin{array}{c}\text { SNR } \\
\mathrm{dB}\end{array}$ & $\begin{array}{c}\mathrm{SE} \\
\mathrm{bit} / \mathrm{s} / \mathrm{Hz}\end{array}$ & NO. & MODCOD & $\begin{array}{c}\text { SNR } \\
\text { dB }\end{array}$ & $\begin{array}{c}\mathrm{SE} \\
\mathrm{bit} / \mathrm{s} / \mathrm{Hz}\end{array}$ & NO. & MODCOD & $\begin{array}{c}\text { SNR } \\
\mathrm{dB}\end{array}$ & $\begin{array}{c}\mathrm{SE} \\
\mathrm{bit} / \mathrm{s} / \mathrm{Hz}\end{array}$ \\
\hline 1 & QPSK 1/4 & -2.4 & 0.456 & 16 & $\begin{array}{c}\text { 16APSK } \\
5 / 9-\mathrm{L}\end{array}$ & 7.06 & 2.039 & 31 & 32APSK 7/9 & 13.36 & 3.579 \\
\hline 2 & $\begin{array}{l}\text { QPSK } \\
13 / 45\end{array}$ & -1.88 & 0.528 & 17 & $\begin{array}{c}\text { 16APSK } \\
\text { 3/5-L }\end{array}$ & 7.72 & 2.204 & 32 & 32APSK 4/5 & 13.87 & 3.682 \\
\hline 3 & QPSK 1/3 & -1.32 & 0.61 & 18 & $\begin{array}{c}16 \text { APSK } \\
28 / 45\end{array}$ & 8.34 & 2.286 & 33 & $\begin{array}{l}\text { 64APSK } \\
\text { 32/45-L }\end{array}$ & 14.46 & 3.916 \\
\hline 4 & QPSK 2/5 & -0.31 & 0.734 & 19 & $\begin{array}{c}\text { 16APSK } \\
\text { 2/3-L }\end{array}$ & 8.71 & 2.45 & 34 & $\begin{array}{c}\text { 64APSK } \\
11 / 15\end{array}$ & 15.31 & 4.039 \\
\hline 5 & QPSK 9/20 & 0.34 & 0.827 & 20 & $\begin{array}{c}\text { 16APSK } \\
2 / 3\end{array}$ & 9.11 & 2.452 & 35 & 64APSK 7/9 & 15.9 & 4.285 \\
\hline 6 & QPSK 1/2 & 1.08 & 0.919 & 21 & $\begin{array}{c}\text { 16APSK } \\
25 / 36\end{array}$ & 9.49 & 2.553 & 36 & 64APSK 4/5 & 16.3 & 4.408 \\
\hline 7 & $\begin{array}{l}\text { QPSK } \\
11 / 20\end{array}$ & 1.59 & 1.012 & 22 & $\begin{array}{c}\text { 16APSK } \\
13 / 18\end{array}$ & 9.94 & 2.656 & 37 & 64APSK 5/6 & 16.98 & 4.592 \\
\hline 8 & QPSK 3/5 & 2.34 & 1.105 & 23 & $\begin{array}{c}\text { 16APSK } \\
3 / 4\end{array}$ & 10.37 & 2.758 & 38 & $\begin{array}{l}\text { 256APSK } \\
29 / 45-L\end{array}$ & 18.2 & 4.721 \\
\hline 9 & QPSK 2/3 & 3.18 & 1.229 & 24 & $\begin{array}{c}\text { 16APSK } \\
7 / 9\end{array}$ & 10.9 & 2.861 & 39 & $\begin{array}{c}\text { 256APSK } \\
2 / 3-\mathrm{L}\end{array}$ & 18.61 & 4.885 \\
\hline 10 & QPSK 3/4 & 4.15 & 1.383 & 25 & $\begin{array}{c}\text { 16APSK } \\
4 / 5\end{array}$ & 11.18 & 2.943 & 40 & $\begin{array}{c}\text { 256APSK } \\
31 / 45-\mathrm{L}\end{array}$ & 19.08 & 5.048 \\
\hline 11 & QPSK 4/5 & 4.79 & 1.476 & 26 & $\begin{array}{c}\text { 32APSK } \\
\text { 2/3-L }\end{array}$ & 11.42 & 3.065 & 41 & $\begin{array}{c}\text { 256APSK } \\
32 / 45\end{array}$ & 19.64 & 5.212 \\
\hline 12 & $\begin{array}{l}\text { 8APSK } \\
26 / 45-L\end{array}$ & 5.29 & 1.595 & 27 & $\begin{array}{c}\text { 16APSK } \\
5 / 6\end{array}$ & 11.78 & 3.068 & 42 & $\begin{array}{c}\text { 256APSK } \\
11 / 15-\mathrm{L}\end{array}$ & 19.98 & 5.376 \\
\hline 13 & $8 P S K$ 3/5 & 5.66 & 1.657 & 28 & $\begin{array}{c}32 \mathrm{APSK} \\
32 / 45\end{array}$ & 12.14 & 3.271 & 43 & $\begin{array}{c}\text { 256APSK } \\
3 / 4\end{array}$ & 20.63 & 5.499 \\
\hline 14 & $\begin{array}{c}\text { 16APSK } \\
1 / 2-\mathrm{L}\end{array}$ & 6.25 & 1.834 & 29 & $\begin{array}{c}32 \mathrm{APSK} \\
11 / 15\end{array}$ & 12.54 & 3.374 & & & & \\
\hline 15 & $8 \mathrm{PSK} 2 / 3$ & 6.68 & 1.844 & 30 & $\begin{array}{c}\text { 32APSK } \\
3 / 4\end{array}$ & 12.98 & 3.451 & & & & \\
\hline
\end{tabular}

\section{Modoc Modes Optimization Algorithm}

After preliminary filter, there still remain 43 MODCODs in Table 1. The optimization should be kept on. Reference [5]-[7] have proposed some procedures to optimize the subset of MODCODs based on DVB-S2. However, these procedures are put forward according to a specific rainfall environment. They divide the MODCODs by quasi-equal intervals and choose the most efficient subset. But as we all know, in most parts of the world the total time of rain is much less than that 
without rain. Moreover, the heavier the rain is, the less likely it is to occur. Accordingly, we propose an algorithm based on the rainfall probability to optimize the MODCOD subset in the view of the DVB-S2X standard. The core is that the selection of MODCODs is based on the MODCOD's probability of use, i.e., adopt the higher and disregard the lower. The algorithm is described as follows:

Firstly, confirm the most efficient MODCOD mode that current link can support based on link analysis, and the subset temporarily consists of MODCODs from NO.1 to the chosen one.

Then, calculate each MODCOD's probability of use. The calculation is as below:

$$
P_{i}=\int_{S N R_{i}}^{S N R_{i+1}} \rho(x) d x
$$

Where $S N R_{i}$ represents the SNR threshold of the itch MODCOD, $\rho(x)$ represents the probability density function (PDF) of the received signal's SNR.

Seek for the MODCOD with the smallest $P_{i}$ except for the NO.1, and prune away it.

Update the subset and repeat step 2 and 3 until the remaining MODCODs meet the requirement.

After the optimization, the SNR intervals between the selected MODCODs are unequal. Due to the high frequency of clear day, higher efficient MODCODs account for a higher proportion whereas inefficient MODCODs occupy less. To ensure the reliability of communication, NO.1 MODCOD mode is compulsory in subset.

\section{Simulation Results}

\subsection{Assumption and precondition.}

The scenario in this paper is composed of a Geostationary Earth Orbit (GEO) satellite whose longitude of sub-satellite point is $92^{\circ} \mathrm{E}$ and a fixed Satellite Terminal (ST) located in Haikou of China. In the simulation scenario the downlink is assumed to use frequency of $20 \mathrm{GHz}$ and horizontal polarization. The power of the satellite is considered $30 \mathrm{~W}$, and the antenna aperture is $2 \mathrm{~m}$. The antenna aperture of ST is preliminarily $0.8 \mathrm{~m}$, and the amplifier noise temperature is set to $300 \mathrm{~K}$. All the antenna efficiency in this work is set to $60 \%$.

To facilitate the simulation, the propagation channel is temporarily subject to rain attenuation. Before calculate each MODCOD's probability of use, we should grasp the PDF of the received signal's SNR $\rho(x)$. We use the Cumulative Distribution Function (CDF) of rain attenuation to deduce it. As we all know, the CDF denotes the relationship between the value of the rain attenuation and the time proportion in long term. If the rain attenuation is nonzero, it means it is rainy, and the higher it is, the heavier the rain is, which results in the lower probability of the high efficient MODCOD.

Firstly, the CDF of the rain attenuation in Haikou is required. According to [9, 10], the attenuation obeys the lognormal distribution, thus the equation of CDF is below:

$$
F(x)=\int_{x}^{\infty} \frac{1}{\sqrt{2 \pi} \sigma t} \exp \left[-\left(\frac{\ln t-m}{\sqrt{2} \sigma}\right)^{2}\right] d t=\frac{1}{2}\left[\operatorname{erfc}\left(\frac{\ln x-m}{\sqrt{2} \sigma}\right)-1\right],
$$

Where $m$ denotes the mean, $\sigma$ for the standard deviation. The value of $m$ and $\sigma$ can be generated according to Rec. ITU-R P.618-10 [9]. The specific position of Haikou is $20.03^{\circ} \mathrm{N}$ latitude, $110.35^{\circ} \mathrm{E}$ longitude, $14.1 \mathrm{~m}$ altitude and $R_{00.1}$ which represents the rain intensity exceeded 0.01 percent of time in an average year is $95 \mathrm{~mm} / \mathrm{h}$ [11]. After calculation, the mean and standard deviation are $m=-2.62$ and $\sigma=1.69$, respectively. The plot of the CDF is Fig. 2. Figure 2 shows that the rain attenuation less than $5 \mathrm{~dB}$ occupy $99.4 \%$ of the whole time. Therefore, it proves that the optimization algorithm based on rainfall probability is reasonable. 


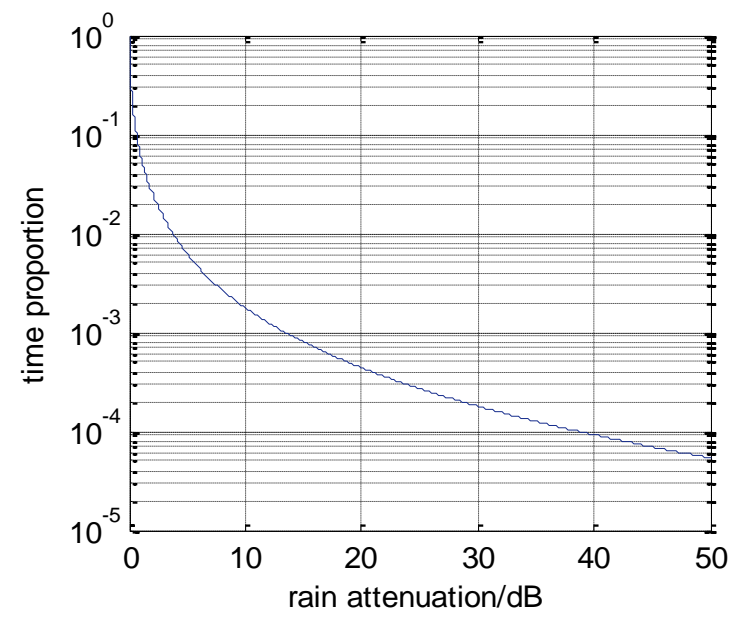

Figure 2. CDF of rain attenuation in Haikou

We can generate Carrier Noise Ratio (CNR) from (3).

$$
\left[\frac{C}{n_{0}}\right]=[E I R P]_{\mathrm{S}}-[L]+\left[\frac{G}{T}\right]_{\mathrm{T}}-[\mathrm{k}]-[m]
$$

Where $[E I R P]_{\mathrm{S}}$ denotes the Effective Isotropic Radiated Power of the satellite; $[L]$ denotes the free space propagation loss between the satellite and ST; $\left[\frac{G}{T}\right]_{\mathrm{T}}$ denotes the quality factor of satellite terminal; $[\mathrm{k}]$ is the Boltzmann constant of $-228.6 \mathrm{~dB}$ and $[m]$ is the rain attenuation. Besides, there should be additional $5 \mathrm{~dB}$ link margin. The values are respectively calculated as: $[E I R P]_{\mathrm{S}}=64.20 \mathrm{~dB}$, $[L]=209.73 \mathrm{~dB},\left[\frac{G}{T}\right]_{\mathrm{T}}=17.49 \mathrm{~dB} / \mathrm{K}$. Then we can get the $\mathrm{SNR}$ of the received signal by $\left[\mathrm{E}_{\mathrm{s}} / \mathrm{n}_{0}\right]$ $=\left[\mathrm{C} / \mathrm{n}_{0}\right]-\left[\mathrm{R}_{\mathrm{est}}\right]$, where $\mathrm{R}_{\mathrm{est}}$ is equal to the transponder bandwidth.

\subsection{Optimization simulation.}

Each MODCOD's probability of use is calculated. Fig. 3 is the distribution of all the preliminary MODCODs' probability of use. It can be observed that most of the preliminary MODCODs are rarely used and redundant. After optimizing, we can get the average spectral efficiency of different subsets, as shown in Fig. 4. It can be deduced that with the increase of quantity of the adopted MODCODs, in the beginning the spectral efficiency increases as well. However, when the quantity arrives at 18, the spectral efficiency gets saturated. Moreover, it is approximately $99.99 \%$ of the efficiency when all MODCODs are adopted. The adopted 18 MODCODs are listed in Table 2. It should be pointed out that the quantity of subset is not fixed, it varies with different request. The subset listed in Table 2 is an advised choice.

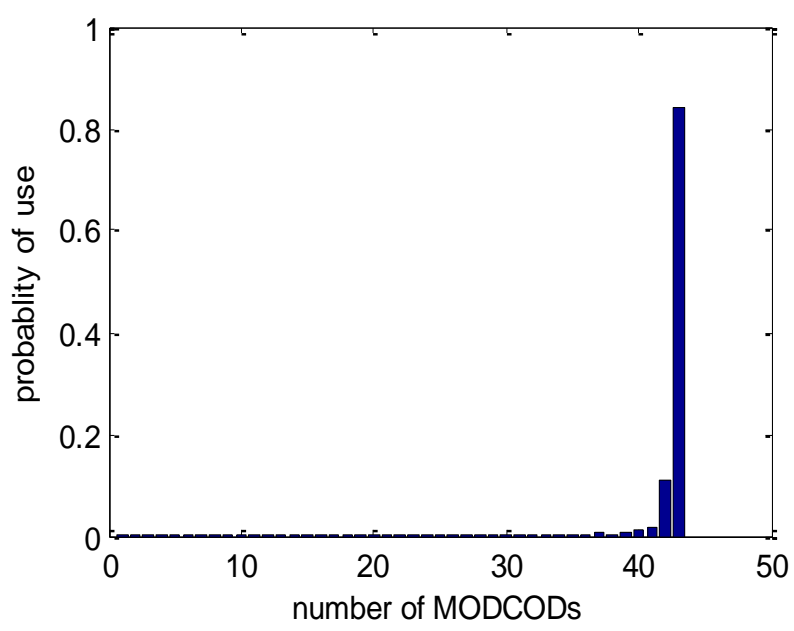

Figure 3. All the preliminary MODCODs' probability of use 


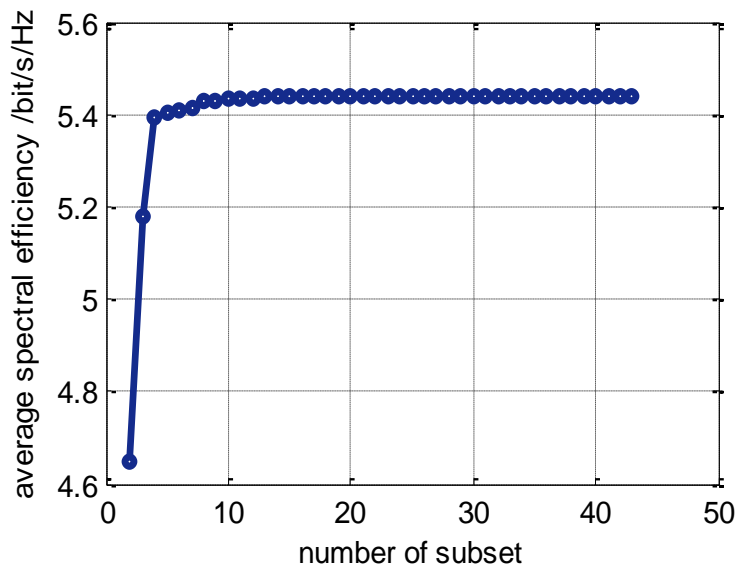

Figure 4. Average spectral efficiency according to different subsets

Table 2. Adopted MODCODs

\begin{tabular}{|c|c|c|c|c|c|c|c|c|c|c|c|}
\hline $\mathrm{JO}$ & ODCOD & & MODCOD & VU. & MODCOD & & MODCOD & & MODCOL & & MODCOD \\
\hline 1 & QPSK 1/4 & 4 & QPSK 2/5 & 16 & $\begin{array}{l}\text { 16APSK } \\
\text { 5/9-L }\end{array}$ & 23 & $\begin{array}{c}\text { 16APSK } \\
3 / 4\end{array}$ & 28 & $\begin{array}{c}\text { 32APSK } \\
32 / 45\end{array}$ & 31 & $\begin{array}{c}\text { 32APSK } \\
7 / 9\end{array}$ \\
\hline 32 & $\begin{array}{c}\text { 32APSK } \\
4 / 5\end{array}$ & 33 & $\begin{array}{l}\text { 64APSK } \\
32 / 45-\mathrm{L}\end{array}$ & 34 & $\begin{array}{c}\text { 64APSK } \\
11 / 15\end{array}$ & 35 & $\begin{array}{c}\text { 64APSK } \\
7 / 9\end{array}$ & 36 & $\begin{array}{c}\text { 64APSK } \\
4 / 5\end{array}$ & 37 & $\begin{array}{c}\text { 64APSK } \\
5 / 6\end{array}$ \\
\hline 38 & $\begin{array}{c}\text { 256APSK } \\
29 / 45-\mathrm{L}\end{array}$ & 39 & $\begin{array}{c}\text { 256APSK } \\
2 / 3-\mathrm{L}\end{array}$ & 40 & $\begin{array}{c}\text { 256APSK } \\
31 / 45-\mathrm{L}\end{array}$ & 41 & $\begin{array}{c}\text { 256APSK } \\
32 / 45\end{array}$ & 42 & $\begin{array}{c}\text { 256APSK } \\
11 / 15-\mathrm{L}\end{array}$ & 43 & $\begin{array}{c}\text { 256APSK } \\
3 / 4\end{array}$ \\
\hline
\end{tabular}

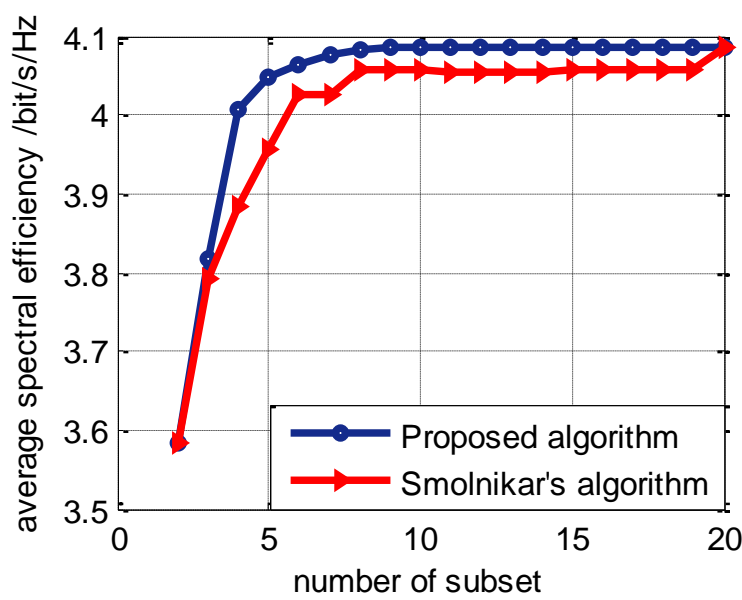

\subsection{Comparison with other algorithm.}

Figure 5. Performance comparison with other algorithm

Because there is no subset optimization based on DVB-S2X in previous research, we adopt the proposed optimization algorithm in DVB-S2 to compare with other algorithm. Smolnikar proposed an optimization algorithm and gave the selected MODCODs based on DVB-S2 [5]. The simulation condition is set the same as that in [5], and the result is shown in Fig. 5. It should be noted that the total MODCODs is reduced from 28 to 20 because of discarding inefficient MODCODs. Figure 5 shows that the optimization algorithm proposed in this paper has an advantage over Smolnikar's. Specifically, the average spectral efficiency is high, and the increase rate is rapid. The proposed algorithm can get almost the same average spectral efficiency only with 5 MODCODs as the Smolnikar's algorithm with 8 MODCODs.

\section{Conclusion}

In this paper we briefly introduce the new DVB-S2X standard and analyze the utilization of MODCOD. Then we put forward an algorithm based on rainfall probability to optimize the 
MODCOD subset. The simulation result indicates that with few MODCODs the system can still achieve high spectral efficiency. And the adopted MODCOD modes can be adjustable for different situation. Moreover, the subset optimization algorithm performs better than the previous algorithm.

\section{Acknowledgments}

This work was supported by National Natural Science Foundations of China (No. 91338201, 91738201 and 91438109).

\section{References}

[1]. ETSI EN 302 307-1 (V1.4.1): "Digital Video Broadcasting (DVB); Second generation framing structure, channel coding and modulation systems for Broadcasting, Interactive Services, News Gathering and other broadband satellite applications; Part I (DVB-S2)," European Telecommunications Standards Institute, November 2014.

[2]. ETSI EN 302 307-2 (V1.1.1): "Digital Video Broadcasting (DVB); Second generation framing structure, channel coding and modulation systems for Broadcasting, Interactive Services, News Gathering and other broadband satellite applications; Part II (DVB-S2X)," European Telecommunications Standards Institute, October 2014.

[3]. S. Coin, Rd. Gaud Enzi and R. Renaldo, "Adaptive coding and modulation for the forward link of broadband satellite networks," in Proceeding of the 46th Global Communications Conference (GLOBECOM'03), San Francisco, USA, vol. 6, December 2003, pp. 3311-3315.

[4]. Koen Williams, "DVB-S2X unpublished. http://www.newtec.eu/frontend/files/userfiles/files/DIALOG/Whitepaper\%20DVB_S2X.pdf

[5]. Miah Smolnikar, Anbazhagan Argument, Michael Motoric, Tomas Javornik and Laurent Castanet, "On transmission modes subset selection in DVB-S2/RCS satellite systems," International Workshop on Satellite and Space Communications (IWSSC), Toulouse, 2008, pp. 263-267.

[6]. Vincent Boussemart, Hartman Brandt and Matteo Berol, "Subset optimization of adaptive coding and modulation schemes for broadband satellite systems," International Conference on Communications(ICC), Cape Town, South Africa, 2010, pp. 1-5.

[7]. Miah Smolnikar, Tomas Javornik and Michael Motoric, "DVB-S2 adaptive coding and modulation for HAP communication system," Vehicular Technology Conference (VTC), Singapore, 2008, pp. 2947-2951.

[8]. DVB-S2/EXT/S2X CALCULATOR https://calculator.newtec.eu/\#/calculator

[9]. ITU-R P.618-10: "Propagation data and prediction methods required for the design of earth-space telecommunication systems," International Telecommunication Union, 2009.

[10]. Shavian Lin, Lidding Zhu, Yenta Goo and Xiao gang Gou, "Distribution characteristics and performance simulations of rain attenuation at Ki band for satellite communications," 5th Global Symposium on Millimeter Waves (GSMM), Harbin, 2012, pp. 579-582.

[11]. Yao Li, Li Xiaoquan and Zhang Lime, "Temporal and spatial distribution characteristics of the rain attenuation in an hour in China," Meteorological, vol. 35-2, Feb 2009, pp. 82-86. 